Review

\title{
mTOR signaling-related MicroRNAs and Cancer involvement
}

\author{
Ping WANG ${ }^{1}$, Xiao-min LIU1,2, Lei DING ${ }^{1}$, Xin-ju ZHANG1, Zhong-liang MA ${ }^{1 凶}$ \\ 1. Lab for Noncoding RNA \& Cancer, School of Life Sciences, Shanghai University, Shanghai, 200444, China \\ 2. School of Environmental Science and Engineering, Shanghai University, Shanghai, 200444, China \\ $\triangle$ Corresponding author: E-mail: zlma@shu.edu.cn \\ (c) Ivyspring International Publisher. This is an open access article distributed under the terms of the Creative Commons Attribution (CC BY-NC) license \\ (https://creativecommons.org/licenses/by-nc/4.0/). See http://ivyspring.com/terms for full terms and conditions.
}

Received: 2017.07.27; Accepted: 2017.12.05; Published: 2018.01.08

\begin{abstract}
MicroRNAs (miRNAs) are a class of single-stranded RNAs, 18-23 nucleotides in length that regulate gene expression at the post-transcriptional level. Dysregulation of miRNAs has been closely associated with the development of cancer. In the process of tumorigenesis, mammalian target of rapamycin (mTOR) plays important roles, and the mTOR signaling pathway is aberrant in various types of human cancers, including non-small cell lung cancer (NSCLC), breast cancer, prostate cancer, as well as others. However, the relationship between miRNAs and the mTOR signaling pathway is indistinct. Herein, we not only summarize the progress of miRNAs and the mTOR signaling pathway in cancers, but also highlight their role in the diagnosis and treatment in the clinic.
\end{abstract}

Key words: miRNA, mTOR, tumorigenesis, cancer

\section{Introduction}

Cancer is one of the most prevalent causes of morbidity and mortality worldwide ${ }^{[1-3]}$. In China, the cancer mortality rate is slightly higher and has been continuously increasing in recent years ${ }^{[4]}$. The development of cancers involves several signaling pathways, such as mammalian target of rapamycin (mTOR), nuclear factor kappa B (NF-kB), mitogen activated kinase-like protein (MAPK) to name a few. Specifically, the mTOR signaling pathway plays an important role in cancer cell proliferation, cell cycle and apoptosis[5].

Through binding to mRNAs' 3'-untranslated region (3'-UTR), miRNAs cause degradation of mRNAs or inhibition of protein translation. As a kind of proto-oncogenes or anti-oncogenes, they can affect the development of cancer directly or indirectly. The progress of the miRNA and mTOR signal pathways have been continuously reported in recent years ${ }^{[6-8]}$. Herein, we focus on the impact of miRNAs on the mTOR signaling pathway in cancer.

\section{mTOR signaling}

Dysregulation of the serine/threonine protein kinase mTOR is linked to tumorgenesis. The mTOR complex includes two parts, mTOR complex 1 (mTORC1) and mTOR complex 2 (mTORC2). Multiproteins comprise mTORC1, including mTOR, regulatory protein associated with $\mathrm{mTOR}$ (raptor), and mammalian lethal with Sec13 protein 8 (mLST8). Three core components compose mTORC2, namely mTOR, rapamycin insensitive companion of mTOR (Rictor), and mLST8.

mTOR belongs to the PI3K-related kinase (PIKK) family. Activated by stress, energy, amino acids, DNA damage, or growth factors, AKT serine/threonine kinase (AKT) or RAS proto-oncogene (Ras) stimulate mTORC1 indirectly ${ }^{[9]}$. This process eventually enables mTORC1 to further affect proliferation, cell growth, and autophagy ${ }^{[10]}$. On the contrary, the anti-oncogene phosphatase and tensin homology deleted on chromosome 10 (PTEN), TSC complex subunit 1 (TSC1), and TSC complex subunit 2 (TSC2) can inhibit the progress of the mTOR pathway. Moreover, Phosphatidylinositol-4,5-bisphosphate 3-kinase (PI3K) activates Phosphatidylinositol-3,4,5-trisphosphate (PIP3) and promotes its translation into 
Phosphatidylinositol-4,5-bisphosphate (PIP2), which in turn, promotes mTORC2, finally promoting proliferation (Figure 1).

\section{mTOR and miRNAs in cancers}

\section{miRNAs regulating $\mathrm{mTORC1}$}

Through targeting genes directly or indirectly, miRNAs are involved in mTORC1 and further influence cell phenotype, including proliferation, metastasis, cell cycle and apoptosis ${ }^{[11-15]}$ (Figure 2).

By downregulating the expression of mTOR, miR-199a can inhibit the proliferation of liver cancer, endometrial cancer, and glioma[16, 17]. Likewise, miR-205 can promote the proliferation of NSCLC by downregulating the expression of PTEN, which is related to the mTOR signaling pathway[18].

The apoptosis of oral squamous cell carcinoma is promoted by miR-218 through the inhibition of the phosphorylation of AKT, a key member of the mTOR signaling pathway[19]. Additionally, miR-101 can inhibit development of carcinoma through indirectly upregulating PTEN[20].

Additionally, miR-22 can inhibit the metastasis of renal cell carcinoma via galectin-1 (Gal-1), playing a novel role in mTOR signaling pathway ${ }^{[21]}$. miR-204

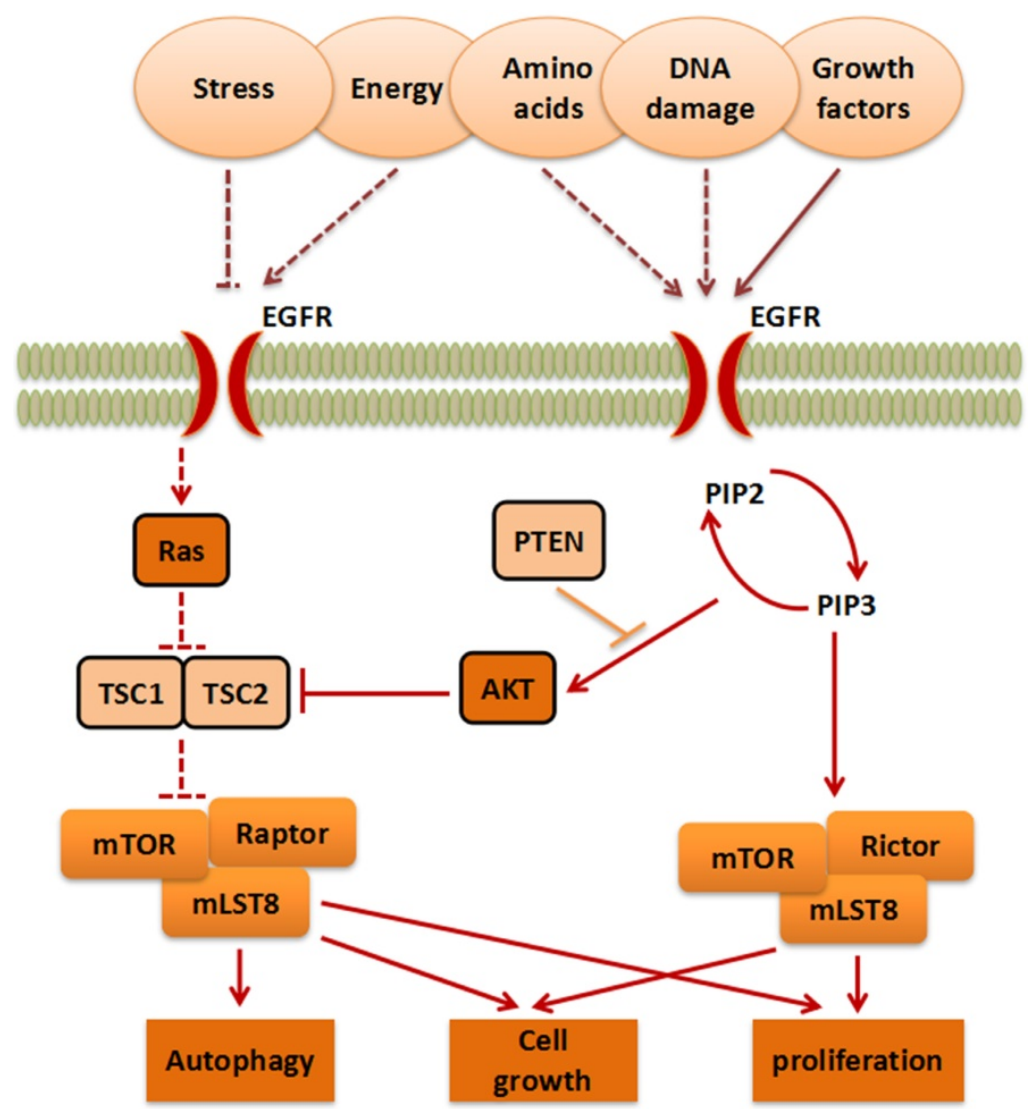

Figure 1. The mTOR signaling pathway. The signaling pathways contain mTORC1 and mTORC2, which are activated by stress, energy, amino acids, DNA damage, and growth factors, to further influence cell growth, autophagy and proliferation. can act as an anti-oncogene by targeting mTOR in breast cancer and ovarian cancer ${ }^{[22]}$. As an important oncogene in the mTOR signaling pathway, mTOR can also be upregulated by miR-451 and thus promote the metastasis of colon cancer[23].

Furthermore, miR-15a and miR-16 can promote drug chemosensitivity in human cervical carcinoma through inducing autophagy, which has a close relationship to the mTOR signaling pathway. As a result, miRNAs can indirectly inhibit tumorgenesis in part through the enhancement of autophagy[24]. However, contrary to miR-376b, miR-129 can promote the process of glioma by autophagy through promoting the mTOR signaling pathway indirectly ${ }^{[2]]}$. There is still debate surrounding the mechanism of autophagy in cancer cells. It is possible that there is a threshold where autophagy can inhibit cancer development, but otherwise promotes oncogenic progression[26, 27].

\section{miRNAs regulating $\mathrm{mTORC2}$}

miRNAs can affect cell survival, integrate metabolism, and bone loss through regulating mTORC2[28, 29] (Figure 3)

miRNAs can influence different cancers via regulating the mTORC2 pathway. miR-153 can act as a potential suppressor factor, which has a vital role in glioma cancer cells. Overexpression of miR-153 can cause significant inhibition of cell growth and activetion of apoptosis via targeting mTORC2[30]. Furthermore, in cervical cancer cells, miR-218 enhances apoptosis and impedes cell cycle through reducing the expression of Rictor[31, 32]. In contrast, miR-21 can promote cell invasion through the induction of mTORC2 expression in renal cancer cells ${ }^{[33]}$.

It has been demonstrated that miR218 could accelerate bone loss through downregulation of Rictor expression ${ }^{[34]}$. Lin-4 and let-7 contribute to inter-tissue transport through the promotion of the mTORC2 pathway[35, 36] (Table 1).

\section{mTOR signaling pathway and cancers}

\section{miRNAs targeting mTOR pathway in lung cancer}

The close relationship between miRNAs and lung cancer has been confirmed by several studies ${ }^{[4,55-59]}$. miRNAs can act within the mTOR signaling pathway by regulating multiple target genes. Through downregulating the expression of PTEN, a vital anti-oncogene in the mTOR signaling 
pathway, miR-10a can promote the proliferation of cancer[60]. miR-503 can inhibit the proliferation of NSCLC by downregulating the expression of phosphoinositide-3-kinase regulatory subunit 1 (p85), and therefore plays an important role in mTOR signaling pathway [61]. Through the suppression of cyclin dependent kinase inhibitor 1A (p21), a significant factor of mTOR signaling pathway, miR-208a can promote the process of NSCLC[62].
miR-31 can suppress the process of NSCLC through inhibiting the expression of MET proto-oncogene, receptor tyrosine kinase (MET) ${ }^{[63]}$, which is related to the mTOR signaling pathway. The relationship between miR-32 and mTOR has already gained much attention. miR-32 can promote proliferation and metastasis of hepatocellular carcinoma cells through directly targeting PTEN[64].

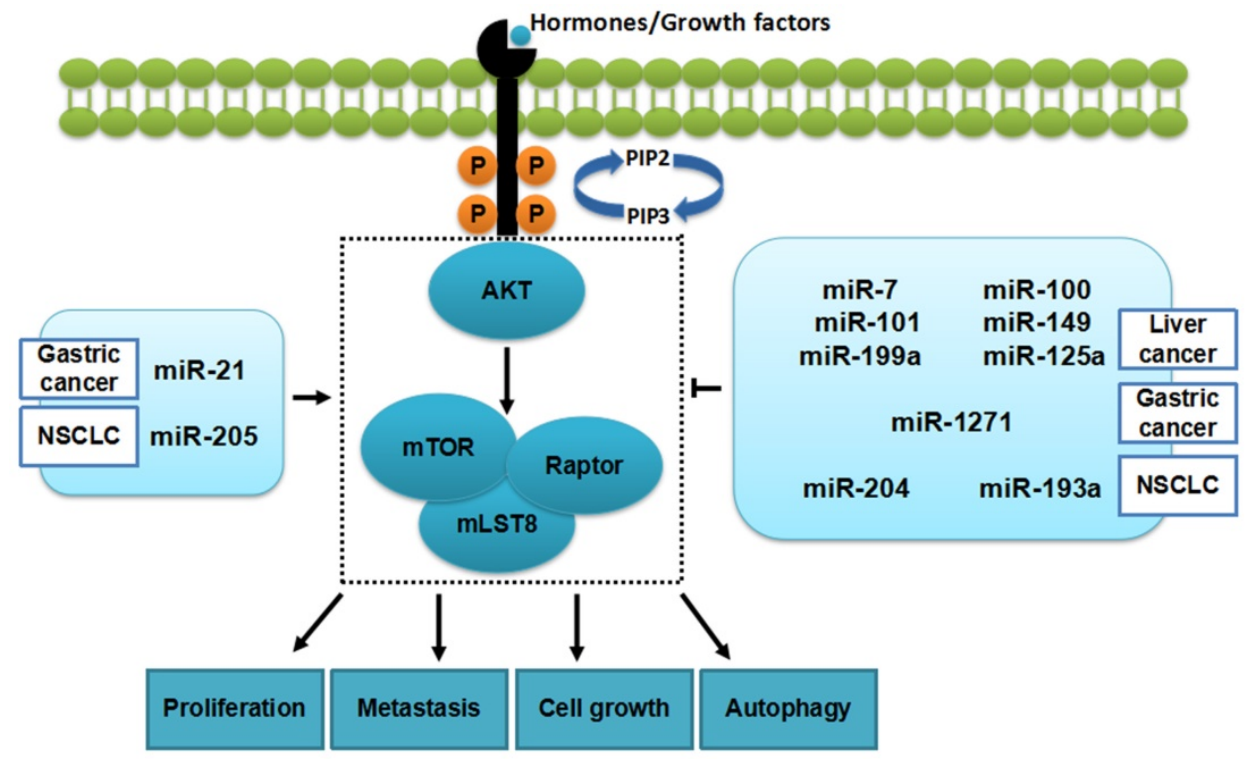

Figure 2. miRNAs and mTORC1 in cancers. Some miRNAs (in the table 1) can inhibit tumorigenesis in cancers by regulating mTORCl while, others promote the development of cancers.

Table 1. miRNAs targeting the mTOR pathway and cancers

\begin{tabular}{|c|c|c|c|c|}
\hline miRNA & Target gene & Cancer & Function & Reference \\
\hline miR-7 & AKT & liver cancer & proliferation, invasion & {$[37]$} \\
\hline miR-22 & mTOR & suprarenal epithelioma & metastasis & [21] \\
\hline miR-99 & mTOR & melanoma & tumor formation & [38] \\
\hline miR-99a & mTOR & $\begin{array}{l}\text { cervical carcinoma, pancreatic cancer, esophageal } \\
\text { squamous cell carcinoma, breast cancer }\end{array}$ & proliferation, invasion, apoptosis & {$[39,40]$} \\
\hline miR-99b & mTOR & pancreatic cancer & proliferation, apoptosis & [41] \\
\hline miR-100 & mTOR & $\begin{array}{l}\text { bladder cancer, oophoroma, } \\
\text { liver cancer }\end{array}$ & $\begin{array}{l}\text { proliferation, cell cycle, autophagy, tumor } \\
\text { formation }\end{array}$ & [42] \\
\hline miR-101 & EZH2 & liver cancer & proliferation, invasion, cell cycle, & [43] \\
\hline miR-125a & mTOR & liver cancer & metastasis & [31] \\
\hline $\operatorname{miR}-125 b$ & mTOR & $\begin{array}{l}\text { sarcoma, } \\
\text { small cell osteosarcoma }\end{array}$ & proliferation, metastasis, cell cycle, apoptosis & {$[44,45]$} \\
\hline miR-149 & mTOR & liver cancer & proliferation & [46] \\
\hline $\mathrm{miR}-193 a-3 p / 5 p$ & mTOR & NSCLC & $\begin{array}{l}\text { proliferation, migration, epithelial mesenchymal } \\
\text { transition (EMT) }\end{array}$ & {$[47]$} \\
\hline miR-199a & mTOR & $\begin{array}{l}\text { gliocytoma, endometrial cancer, } \\
\text { liver cancer }\end{array}$ & proliferation & {$[17]$} \\
\hline miR-204 & mTOR & NSCLC, oophoroma & metastasis & [48] \\
\hline miR-634 & mTOR & cervical carcinoma & proliferation, metastasis, apoptosis & [49] \\
\hline miR-21 & TSC & gastric cancer, lymphadenoma & proliferation, cell cycle & [50] \\
\hline $\operatorname{miR}-1271$ & mTOR & gastric cancer & proliferation, apoptosis & [51] \\
\hline miR-96 & mTOR & prostatic cancer & proliferation, metastasis & [52] \\
\hline miR-155 & AKT & cervical cancer & autophagy & [53] \\
\hline miR-205 & PTEN & NSCLC & proliferation, angiogenesis & [18] \\
\hline miR-451 & mTOR & colon cancer & proliferation, migration & [23] \\
\hline miR-532-5p & mTOR & gastric cancer & proliferation, metastasis & [54] \\
\hline
\end{tabular}


As a vital regulator of the mTOR signaling pathway, epidermal growth factor receptor (EGFR) has a significant influence on the pathway itself and other cancers ${ }^{[65-68]}$. EGFR could activate the mTOR signaling pathway through growth factors or other factors (Figure 1). We proved that miR-107-5p and miR-34a could directly target EGFR to further inhibit cell proliferation, restrain metastasis, impede cell cycle, and promote apoptosis in vitro, furthermore, they could inhibit proliferation by directly targeting EGFR in vivo[69, 70]. miR-34a also has been found to inhibit proliferation of cancer cells through downregulating AKT in glioma stem cells[71].

\section{miRNAs targeting $\mathrm{mTOR}$ in breast and prostate cancers}

Breast cancer is a malignant disease affecting females worldwide, and has attracted more and more attention over the years $[4,72]$. The cell cycle of breast cancer can be impeded by miR-100, and its apoptosis promoted through the downregulation of the mTOR signaling pathway ${ }^{[73,74]}$. Furthermore, miR-125b can inhibit the expression of mTOR, thus inhibiting the process of breast cancer. Moreover, reducing drug resistance in breast cancer plays a positive role in treatment ${ }^{[75]}$. Other studies have also confirmed the inhibitory effect of miR-15, miR-16, and miR-99a in breast cancer ${ }^{[76-78]}$.

Moreover, miR-25a and miR-25b can inhibit the

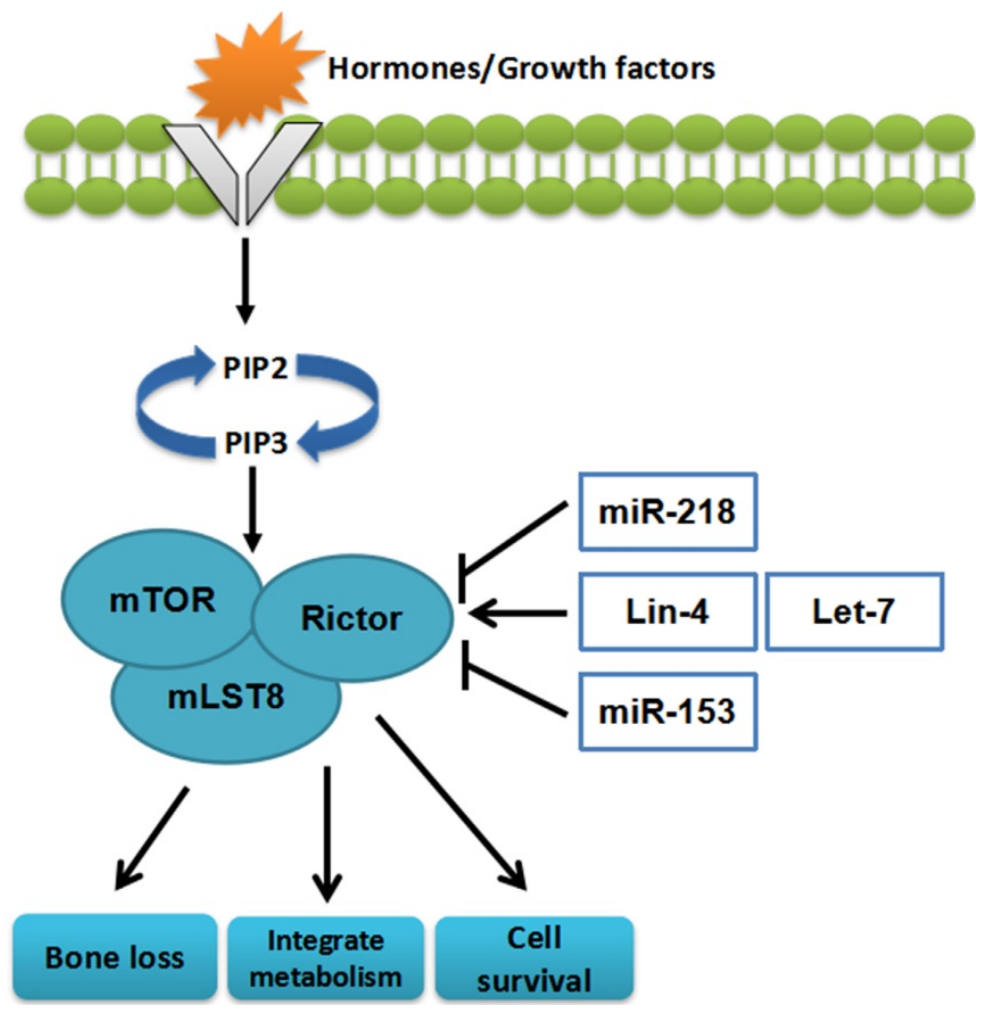

Figure 3. The miRNAs targeting mTORC2. miRNAs can influence cell survival, bone loss, and integrate metabolism through regulating $\mathrm{mTORC2}$ migration of prostate cancer through directly targeting la ribonucleoprotein domain family member 1 (LARP1), which is related to mTOR ${ }^{[79]}$. In prostate cancer, miR-29b has been found to inhibit cancer development by downregulating mTOR signaling ${ }^{[80]}$. Males diagnosed with prostate cancer have a high rate of morbidity and mortality. We speculate that this disease could be one step closer to being overcome through investigating the relationship between miRNAs and the mTOR pathway in prostate cancer.

\section{miRNAs targeting the MTOR pathway in other cancers}

miRNAs influence tumorigenesis in a diverse subset of cancers via the mTOR pathway, including hepatocellular carcinoma (HCC). Overexpression of miR-1207-5p exhibited a negative regulatory function on HCC through suppressing the expression of the mTOR pathway [81]. Besides, other groups have proved that miR-345, miR-221, and miR-223 could inhibit the development of HCC by mediating the mTOR pathway[82-84]. A decrease in drug resistance can be achieved through miR-130a, miR-100 and miR-199a's modulation of the expression of the mTOR pathway in ovarian cancer ${ }^{[85-87]}$. In gastric cancer, miR-224 can promote the development of cell growth and metastasis through activation of the mTOR pathway[88, ${ }^{89}$. Inversely, miR-370 could inhibit tumorgenesis by restraining the mTOR pathway of gastric cancer cells[90, 91]. Studies have also demonstrated that miRNAs could downregulate the expression of the mTOR pathway to inhibit the invasion and migration of colorectal cancer cells s92-94]. $^{\text {. }}$

As known to all, the serine/ threonine kinase B-Raf (BRAF), a proto-oncogene, has a close relationship with the mTOR pathway[95-97]. BRAF plays an important role as a therapeutic target in the treatment of melanoma[98]. Studies have shown that miR-146b, miR-302, and miR-378-5p can impede the development of cancer through binding to the 3'-UTR of BRAF, which provides a new avenue for targeted therapy ${ }^{[99-102]}$. More studies are needed to expand upon and detail the therapeutic target genes of the mTOR signaling pathway that are stimulated by miRNAs.

\section{Conclusion and Future perspectives}

In conclusion, miRNAs can, on the one hand, influence the proliferation, metastasis, apoptosis, and cell cycle of different cancer cells through targeting the mTOR signaling 
pathway. On the other hand, miRNAs are known to reach phase I clinical trials, importantly acting as a cancer diagnosis index[103, 104]. Moreover, some miRNAs can be combined with other non-coding RNAs to inhibit tumor progress and development ${ }^{[105]}$.

Precision medicine has drawn more and more attention recently as an elegant and effective approach to battling this serious and widespread disease. Our lab has demonstrated that the miRNAs, miR-34a, miR-107-5p, miR-18a-5p, miR-146a-5p, miR-32, miR181a-5p, and miR-486-5p have important functions in the progress of lung cancer[69, 106-111]. In NSCLC cells, miR-34a, miR-107-5p, and miR-146-5p function as suppressors by targeting the oncogenic genes, transforming growth factor beta receptor 2 (TGF $\beta R 2$ ), EGFR, and cyclin D1 (CCND1)/cyclin D2 (CCND2) respectively, resulting in the inhibition of proliferation, metastasis, and cell cycle and promoting apoptosis[69, 106, 111]. While we found that miR-18a-5p and miR-150 act as oncogenic factors, increasing proliferation and cell cycle, we also found that miR-18a-5p promotes autophagy $[108,112]$. In addition, we demonstrated that miR-32a can inhibit proliferation, cell cycle, and promote apoptosis, that miR-181a-5p restrains cell proliferation and migration in NSCLC, and that miR-486-5p is a negative regulator of NSCLC through inhibiting cell growth and impeding cell cycle[107, 109,110]. These miRNAs are related to the tumorigenesis of NSCLC and can become molecular diagnostic tools in the treatment of lung cancer.

In patients, the mTOR signaling pathway is linked to a poor prognosis. As a result, it exposes a new possible target for the diagnosis and treatment of cancer[113, 114]. Some miRNAs, such as miR-16, have been in drug development and have been tested for safety and activity in patients who suffer from recurrent malignant pleural mesothelioma ${ }^{[115]}$. Furthermore, miR-34a could become the first miRNA to reach phase I clinical trials[70]. Moreover, some microRNAs can be regarded as diagnosis markers for cancer ${ }^{[116-118]}$. In recent years, new types of non-coding RNA, such as tRNA-derived small RNA (tRF) and circular RNA (circRNA), have been identified in diverse cancers and confirmed to play an import role in tumorigenesis. Therefore, we believe there is a network of non-coding RNA regulating cell progress. What's more, non-coding RNA could have an important role in cancer stem cells. Last but not least, personalized medicine catered to each patient will be advocated for the treatment of cancer in the future. There is no doubt that the study of miRNAs or the mTOR signaling pathway will arouse increasing attention.

\section{Competing Interests}

The authors have declared that no competing interest exists.

\section{References}

1. Quader S, Kataoka K. Nanomaterial-Enabled Cancer Therapy. Molecular therapy : the journal of the American Society of Gene Therapy. 2017; 25: 1501-13.

2. McGuire S. World Cancer Report 2014. Geneva, Switzerland: World Health Organization, International Agency for Research on Cancer, WHO Press, 2015. Advances in nutrition. 2016; 7: 418-9.

3. Stefan N, Haring HU, Hu FB, Schulze MB. Divergent associations of height with cardiometabolic disease and cancer: epidemiology, pathophysiology, and global implications. The lancet Diabetes \& endocrinology. 2016; 4: 457-67.

4. Chen W, Zheng R, Baade PD, Zhang S, Zeng H, Bray F, et al. Cancer statistics in China, 2015. CA Cancer J Clin. 2016; 66: 115-32.

5. Zhu M, Wang M, Yang F, Tian Y, Cai J, Yang H, et al. miR-155-5p inhibition promotes the transition of bone marrow mesenchymal stem cells to gastric cancer tissue derived MSC-like cells via NF-kappaB p65 activation. Oncotarget. 2016.

6. Alqurashi N, Hashimi SM, Wei MQ. Chemical Inhibitors and microRNAs (miRNA) Targeting the Mammalian Target of Rapamycin (mTOR) Pathway: Potential for Novel Anticancer Therapeutics. International journal of molecular sciences. 2013; 14: 3874-900.

7. Meng XM, Nikolic-Paterson DJ, Lan HY. TGF-beta: the master regulator of fibrosis. Nature reviews Nephrology. 2016; 12: 325-38.

8. Kopczynska E. Role of microRNAs in the resistance of prostate cancer to docetaxel and paclitaxel. Contemporary oncology. 2015; 19: 423-7.

9. Brotelle T, Bay JO. [PI3K-AKT-mTOR pathway: Description, therapeutic development, resistance, predictive/prognostic biomarkers and therapeutic applications for cancer]. Bull Cancer. 2016; 103: 18-29.

10. Fantus D, Rogers NM, Grahammer F, Huber TB, Thomson AW. Roles of mTOR complexes in the kidney: implications for renal disease and transplantation. Nature reviews Nephrology. 2016; 12: 587-609.

11. Iliopoulos D, Polytarchou C, Hatziapostolou M, Kottakis F, Maroulakou IG, Struhl K, et al. MicroRNAs differentially regulated by Akt isoforms control EMT and stem cell renewal in cancer cells. Sci Signal. 2009; 2: ra62.

12. Xie J, Wang X, Proud CG. mTOR inhibitors in cancer therapy. F1000Research. 2016; 5 .

13. Zeng $\mathrm{Y}$, Wang $\mathrm{KX}, \mathrm{Xu} \mathrm{H}$, Hong $\mathrm{Y}$. Integrative miRNA analysis identifies hsa-miR-3154, hsa-miR-7-3, and hsa-miR-600 as potential prognostic biomarker for cervical cancer. Journal of cellular biochemistry. 2017.

14. Yang J, Liu R, Deng Y, Oian J, Lu Z, Wang Y, et al. MiR-15a/16 deficiency enhances anti-tumor immunity of glioma-infiltrating CD8+ T cells through targeting mTOR. International journal of cancer. 2017.

15. Zhou W, Liu L, Xue Y, Zheng J, Liu X, Ma J, et al. Combination of Endothelial-Monocyte-Activating Polypeptide-II with Temozolomide Suppress Malignant Biological Behaviors of Human Glioblastoma Stem Cells via miR-590-3p/MACC1 Inhibiting PI3K/AKT/mTOR Signal Pathway. Frontiers in molecular neuroscience. 2017; 10: 68

16. Li W, Wang H, Zhang J, Zhai L, Chen W, Zhao C. miR-199a-5p regulates beta1 integrin through Ets-1 to suppress invasion in breast cancer. Cancer science. 2016; 107: 916-23.

17. Shen L, Sun C, Li Y, Li X, Sun T, Liu C, et al. MicroRNA-199a-3p suppresses glioma cell proliferation by regulating the AKT/mTOR signaling pathway. Tumour biology : the journal of the International Society for Oncodevelopmental Biology and Medicine. 2015; 36: 6929-38.

18. Cai J, Fang L, Huang Y, Li R, Yuan J, Yang Y, et al. miR-205 targets PTEN and PHLPP2 to augment AKT signaling and drive malignant phenotypes in non-small cell lung cancer. Cancer research. 2013; 73: 5402-15.

19. Uesugi A, Kozaki K, Tsuruta T, Furuta M, Morita K, Imoto I, et al. The tumor suppressive microRNA miR-218 targets the mTOR component Rictor and inhibits AKT phosphorylation in oral cancer. Cancer research. 2011; 71: 5765-78.

20. Lin C, Huang F, Li QZ, Zhang YJ. miR-101 suppresses tumor proliferation and migration, and induces apoptosis by targeting EZH2 in esophageal cancer cells. International journal of clinical and experimental pathology. 2014; 7: 6543-50.

21. White NM, Masui O, Newsted D, Scorilas A, Romaschin AD, Bjarnason GA, et al. Galectin-1 has potential prognostic significance and is implicated in clear cell renal cell carcinoma progression through the HIF/mTOR signaling axis. British journal of cancer. 2014; 110: 1250-9.

22. Imam JS, Plyler JR, Bansal H, Prajapati S, Bansal S, Rebeles J, et al. Genomic loss of tumor suppressor miRNA-204 promotes cancer cell migration and invasion by activating AKT/mTOR/Rac1 signaling and actin reorganization. PloS one. 2012; 7: e52397.

23. Chen MB, Wei MX, Han JY, Wu XY, Li C, Wang J, et al. MicroRNA-451 regulates AMPK/mTORC1 signaling and fascin1 expression in HT-29 colorectal cancer. Cell Signal. 2014; 26: 102-9. 
24. Huang N, Wu J, Qiu W, Lyu Q, He J, Xie W, et al. MiR-15a and miR-16 induce autophagy and enhance chemosensitivity of Camptothecin. Cancer biology \& therapy. 2015; 16: 941-8.

25. Chen X, Zhang Y, Shi Y, Lian H, Tu H, Han S, et al. MiR-129 triggers autophagic flux by regulating a novel Notch-1/ E2F7/Beclin-1 axis to impair the viability of human malignant glioma cells. Oncotarget. 2016; 7: 9222-35.

26. Korkmaz G, le Sage C, Tekirdag KA, Agami R, Gozuacik D. miR-376b controls starvation and mTOR inhibition-related autophagy by targeting ATG4C and BECN1. Autophagy. 2012; 8: 165-76

27. Zhou H, Yuan M, Yu Q, Zhou X, Min W, Gao D. Autophagy regulation and its role in gastric cancer and colorectal cancer. Cancer biomarkers : section A of Disease markers. 2016; 17: 1-10.

28. Zhang Y, Huang B, Wang HY, Chang A, Zheng XFS. Emerging Role of MicroRNAs in mTOR Signaling. Cellular and molecular life sciences : CMLS. 2017; 74: 2613-25.

29. Jang HJ, Lee HS, Burt BM, Lee GK, Yoon KA, Park YY, et al. Integrated genomic analysis of recurrence-associated small non-coding RNAs in oesophageal cancer. Gut. 2017; 66: 215-25.

30. Cui Y, Zhao J, Yi L, Jiang Y. microRNA-153 Targets mTORC2 Component Rictor to Inhibit Glioma Cells. PloS one. 2016; 11: e0156915.

31. Tang H, Li RP, Liang P, Zhou YL, Wang GW. miR-125a inhibits the migration and invasion of liver cancer cells via suppression of the PI3K/AKT/mTOR signaling pathway. Oncology letters. 2015; 10: 681-6.

32. Liang $\mathrm{B}, \mathrm{Li} \mathrm{Y}$, Wang $\mathrm{T}$. A three miRNAs signature predicts survival in cervical cancer using bioinformatics analysis. Scientific reports. 2017; 7: 5624

33. Bera A, Das F, Ghosh-Choudhury N, Kasinath BS, Abboud HE, Choudhury GG. microRNA-21-induced dissociation of PDCD4 from rictor contributes to Akt-IKKbeta-mTORC1 axis to regulate renal cancer cell invasion. Experimental cell research. 2014; 328: 99-117.

34. Lai P, Song Q, Yang C, Li Z, Liu S, Liu B, et al. Loss of Rictor with aging in osteoblasts promotes age-related bone loss. Cell death \& disease. 2016; 7: e2408.

35. Dowen RH, Breen PC, Tullius T, Conery AL, Ruvkun G. A microRNA program in the C. elegans hypodermis couples to intestinal mTORC2/PQM-1 signaling to modulate fat transport. Genes \& development. 2016; 30: 1515-28.

36. Weaver BP, Sewell AK, Han M. Time to move the fat. Genes \& development. 2016; 30: 1481-2.

37. Fang Y, Xue JL, Shen Q, Chen J, Tian L. MicroRNA-7 inhibits tumor growth and metastasis by targeting the phosphoinositide 3-kinase/Akt pathway in hepatocellular carcinoma. Hepatology. 2012; 55: 1852-62.

38. Sun D, Lee YS, Malhotra A, Kim HK, Matecic M, Evans C, et al. miR-99 family of MicroRNAs suppresses the expression of prostate-specific antigen and prostate cancer cell proliferation. Cancer research. 2011; 71: 1313-24.

39. Yang Z, Han Y, Cheng K, Zhang G, Wang X. miR-99a directly targets the mTOR signalling pathway in breast cancer side population cells. Cell Prolif. 2014; 47: 587-95.

40. Huang $\mathrm{X}$, Huang L, Shao $\mathrm{M}$. Aquaporin 3 facilitates tumor growth in pancreatic cancer by modulating mTOR signaling. Biochemical and biophysical research communications. 2017; 486: 1097-102.

41. Wei F, Liu Y, Guo Y, Xiang A, Wang G, Xue X, et al. miR-99b-targeted mTOR induction contributes to irradiation resistance in pancreatic cancer. Mol Cancer. 2013; 12: 81.

42. Ge YY, Shi Q, Zheng ZY, Gong J, Zeng C, Yang J, et al. MicroRNA-100 promotes the autophagy of hepatocellular carcinoma cells by inhibiting the expression of mTOR and IGF-1R. Oncotarget. 2014; 5: 6218-28.

43. Xu L, Beckebaum S, Iacob S, Wu G, Kaiser GM, Radtke A, et al. MicroRNA-101 inhibits human hepatocellular carcinoma progression through EZH2 downregulation and increased cytostatic drug sensitivity. Journal of hepatology. 2014; 60: 590-8.

44. Li J, You T, Jing J. MiR-125b inhibits cell biological progression of Ewing's sarcoma by suppressing the PI3K/Akt signalling pathway. Cell Prolif. 2014; 47: $152-60$.

45. Xie L, Liao Y, Shen L, Hu F, Yu S, Zhou Y, et al. Identification of the miRNA-mRNA regulatory network of small cell osteosarcoma based on RNA-seq. Oncotarget. 2017; 8: 42525-36.

46. Zhang Y, Guo X, Xiong L, Yu L, Li Z, Guo Q, et al. Comprehensive analysis of microRNA-regulated protein interaction network reveals the tumor suppressive role of microRNA-149 in human hepatocellular carcinoma via targeting AKT-mTOR pathway. Mol Cancer. 2014; 13: 253

47. Yu T, Li J, Yan M, Liu L, Lin H, Zhao F, et al. MicroRNA-193a-3p and $-5 p$ suppress the metastasis of human non-small-cell lung cancer by downregulating the ERBB4/PIK3R3/mTOR/S6K2 signaling pathway. Oncogene. 2015; 34: 413-23.

48. Shi L, Zhang B, Sun X, Lu S, Liu Z, Liu Y, et al. MiR-204 inhibits human NSCLC metastasis through suppression of NUAK1. British journal of cancer. 2014; 111: 2316-27.

49. Cong J, Liu R, Wang X, Jiang H, Zhang Y. MiR-634 decreases cell proliferation and induces apoptosis by targeting mTOR signaling pathway in cervical cancer cells. Artif Cells Nanomed Biotechnol. 2015: 1-8.

50. Go H, Jang JY, Kim PJ, Kim YG, Nam SJ, Paik JH, et al. MicroRNA-21 plays an oncogenic role by targeting FOXO1 and activating the PI3K/AKT pathway in diffuse large B-cell lymphoma. Oncotarget. 2015; 6: 15035-49.

51. Yang M, Shan X, Zhou X, Qiu T, Zhu W, Ding Y, et al. miR-1271 regulates cisplatin resistance of human gastric cancer cell lines by targeting IGF1R, IRS1, mTOR, and BCL2. Anticancer Agents Med Chem. 2014; 14: 884-91.
52. Siu MK, Tsai YC, Chang YS, Yin JJ, Suau F, Chen WY, et al. Transforming growth factor-beta promotes prostate bone metastasis through induction of microRNA-96 and activation of the mTOR pathway. Oncogene. 2015; 34: 4767-76.

53. Wan G, Xie W, Liu Z, Xu W, Lao Y, Huang N, et al. Hypoxia-induced MIR155 is a potent autophagy inducer by targeting multiple players in the MTOR pathway. Autophagy. 2014; 10: 70-9.

54. Xu X, Zhang $Y$, Liu Z, Zhang $X$, Jia J. miRNA-532-5p functions as an oncogenic microRNA in human gastric cancer by directly targeting RUNX3. J Cell Mol Med. 2016; 20: 95-103.

55. Del Vescovo V, Denti MA. microRNA and Lung Cancer. Adv Exp Med Biol. 2015; 889: 153-77.

56. Qin X, Yu S, Zhou L, Shi M, Hu Y, Xu X, et al. Cisplatin-resistant lung cancer cell-derived exosomes increase cisplatin resistance of recipient cells in exosomal miR-100-5p-dependent manner. International journal of nanomedicine. 2017; 12: 3721-33.

57. Duan B, Guo T, Sun H, Cai R, Rui Q, Xi Z. miR-205 as a biological marker in non-small cell lung cancer. Biomedicine \& pharmacotherapy $=$ Biomedecine \& pharmacotherapie. 2017; 91: 823-30.

58. Wang $Y$, Chen T, Huang H, Jiang Y, Yang L, Lin Z, et al. miR-363-3p inhibits tumor growth by targeting PCNA in lung adenocarcinoma. Oncotarget. 2017; 8: 20133-44

59. Jiang W, Zhang W, Wu L, Liu L, Men Y, Wang J, et al. MicroRNA-Related Polymorphisms in PI3K/Akt/mTOR Pathway Genes Are Predictive of Limited-Disease Small Cell Lung Cancer Treatment Outcomes. BioMed research international. 2017; 2017: 6501385.

60. Yu T, Liu L, Li J, Yan M, Lin H, Liu Y, et al. MiRNA-10a is upregulated in NSCLC and may promote cancer by targeting PTEN. Oncotarget. 2015; 6: 30239-50.

61. Yang Y, Liu L, Zhang Y, Guan H, Wu J, Zhu X, et al. MiR-503 targets PI3K p85 and IKK-beta and suppresses progression of non-small cell lung cancer. International journal of cancer. 2014; 135: 1531-42.

62. Tang Y, Cui Y, Li Z, Jiao Z, Zhang Y, He Y, et al. Radiation-induced miR-208a increases the proliferation and radioresistance by targeting p21 in human lung cancer cells. J Exp Clin Cancer Res. 2016; 35: 7.

63. Hou C, Sun B, Jiang Y, Zheng J, Yang N, Ji C, et al. MicroRNA-31 inhibits lung adenocarcinoma stem-like cells via down-regulation of MET-PI3K-Akt signaling pathway. Anticancer Agents Med Chem. 2016; 16: 501-18.

64. Yan SY, Chen MM, Li GM, Wang YQ, Fan JG. MiR-32 induces cell proliferation, migration, and invasion in hepatocellular carcinoma by targeting PTEN. Tumour biology : the journal of the International Society for Oncodevelopmental Biology and Medicine. 2015; 36: 4747-55.

65. Maemondo M, Inoue A, Kobayashi K, Sugawara S, Oizumi S, Isobe H, et al. Gefitinib or chemotherapy for non-small-cell lung cancer with mutated EGFR. The New England journal of medicine. 2010; 362: 2380-8.

66. Choi YJ, Lee DH, Choi CM, Lee JS, Lee SJ, Ahn JH, et al. Randomized phase II study of paclitaxel/carboplatin intercalated with gefitinib compared to paclitaxel/carboplatin alone for chemotherapy-naive non-small cell lung cancer in a clinically selected population excluding patients with non-smoking adenocarcinoma or mutated EGFR. BMC cancer. 2015; 15: 763

67. Liu X, Wang P, Zhang C, Ma Z. Epidermal growth factor receptor (EGFR): A rising star in the era of precision medicine of lung cancer. Oncotarget. 2017.

68. Chen Y, Zhou X, Qiao J, Bao A. MiR-142-3p Overexpression Increases Chemo-Sensitivity of NSCLC by Inhibiting HMGB1-Mediated Autophagy. Cellular physiology and biochemistry : international journal of experimental cellular physiology, biochemistry, and pharmacology. 2017; 41: 1370-82.

69. Wang P, Liu X, Shao Y, Wang H, Liang C, Han B, et al. MicroRNA-107-5p suppresses non-small cell lung cancer by directly targeting oncogene epidermal growth factor receptor. Oncotarget. 2017.

70. Li YL, Liu XM, Zhang CY, Zhou JB, Shao Y, Liang C, et al. MicroRNA-34a/EGFR axis plays pivotal roles in lung tumorigenesis. Oncogenesis. 2017; 6: e372

71. Rathod SS, Rani SB, Khan M, Muzumdar D, Shiras A. Tumor suppressive miRNA-34a suppresses cell proliferation and tumor growth of glioma stem cells by targeting Akt and Wnt signaling pathways. FEBS Open Bio. 2014; 4: $485-95$.

72. Zhou S, Li J, Xu H, Zhang S, Chen X, Chen W, et al. Liposomal curcumin alters chemosensitivity of breast cancer cells to Adriamycin via regulating microRNA expression. Gene. 2017; 622: 1-12.

73. Zhang B, Zhao R, He Y, Fu X, Fu L, Zhu Z, et al. MicroRNA 100 sensitizes luminal A breast cancer cells to paclitaxel treatment in part by targeting mTOR. Oncotarget. 2016; 7: 5702-14.

74. Pakravan K, Babashah S, Sadeghizadeh M, Mowla SJ, Mossahebi-Mohammadi M, Ataei F, et al. MicroRNA-100 shuttled by mesenchymal stem cell-derived exosomes suppresses in vitro angiogenesis through modulating the mTOR/HIF-1alpha/VEGF signaling axis in breast cancer cells. Cellular oncology. 2017.

75. Vilquin P, Donini CF, Villedieu M, Grisard E, Corbo L, Bachelot T, et al. MicroRNA-125b upregulation confers aromatase inhibitor resistance and is a novel marker of poor prognosis in breast cancer. Breast cancer research : BCR. 2015; $17: 13$.

76. Janaki Ramaiah M, Lavanya A, Honarpisheh M, Zarea M, Bhadra U, Bhadra MP. MiR-15/16 complex targets p70S6 kinase 1 and controls cell proliferation in MDA-MB-231 breast cancer cells. Gene. 2014; 552: 255-64 
77. Hu Y, Zhu Q, Tang L. MiR-99a antitumor activity in human breast cancer cells through targeting of mTOR expression. PloS one. 2014; 9: e92099.

78. Zhang ZW, Guo RW, Lv JL, Wang XM, Ye JS, Lu NH, et al. MicroRNA-99a inhibits insulin-induced proliferation, migration, dedifferentiation, and rapamycin resistance of vascular smooth muscle cells by inhibiting insulin-like growth factor-1 receptor and mammalian target of rapamycin. Biochemical and biophysical research communications. 2017; 486: 414-22.

79. Kato M, Goto Y, Matsushita R, Kurozumi A, Fukumoto I, Nishikawa R, et al. MicroRNA-26a/b directly regulate La-related protein 1 and inhibit cancer cell invasion in prostate cancer. International journal of oncology. 2015; 47: 710-8.

80. Takayama K, Misawa A, Suzuki T, Takagi K, Hayashizaki Y, Fujimura T, et al. TET2 repression by androgen hormone regulates global hydroxymethylation status and prostate cancer progression. Nature communications. 2015; 6: 8219.

81. Zhao G, Dong L, Shi H, Li H, Lu X, Guo X, et al. MicroRNA-1207-5p inhibits hepatocellular carcinoma cell growth and invasion through the fatty acid synthase-mediated Akt/mTOR signalling pathway. Oncology reports. 2016; 36: 1709-16.

82. Dong Z, Qi R, Guo X, Zhao X, Li Y, Zeng Z, et al. MiR-223 modulates hepatocellular carcinoma cell proliferation through promoting apoptosis via the Rab1-mediated mTOR activation. Biochemical and biophysical research communications. 2017; 483: 630-7.

83. Yu M, Xue H, Wang Y, Shen Q, Jiang Q, Zhang X, et al. miR-345 inhibits tumor metastasis and EMT by targeting IRF1-mediated mTOR/STAT3/AKT pathway in hepatocellular carcinoma. International journal of oncology. 2017; 50: 975-83.

84. Kim J, Jiang J, Badawi M, Schmittgen TD. miR-221 regulates CD44 in hepatocellular carcinoma through the PI3K-AKT-mTOR pathway. Biochemical and biophysical research communications. 2017; 487: 709-15.

85. Zhang HD, Jiang LH, Sun DW, Li J, Ji ZL. The role of miR-130a in cancer. Breast cancer. 2017; 24: 521-7.

86. Guo $\mathrm{P}$, Xiong $\mathrm{X}$, Zhang S, Peng D. miR-100 resensitizes resistant epithelial ovarian cancer to cisplatin. Oncology reports. 2016; 36: 3552-8.

87. Wu D, Huang HJ, He CN, Wang KY. MicroRNA-199a-3p regulates endometrial cancer cell proliferation by targeting mammalian target of rapamycin (mTOR). Int J Gynecol Cancer. 2013; 23: 1191-7.

88. Zhang Y, Li CF, Ma LJ, Ding M, Zhang B. MicroRNA-224 aggrevates tumor growth and progression by targeting $\mathrm{mTOR}$ in gastric cancer. International journal of oncology. 2016; 49: 1068-80.

89. Xu N, Lian YJ, Dai X, Wang YJ. miR-7 Increases Cisplatin Sensitivity of Gastric Cancer Cells Through Suppressing mTOR. Technology in cancer research \& treatment. 2017: 1533034617717863.

90. Zeng Y, Fu M, Wu GW, Zhang AZ, Chen JP, Lin HY, et al. Upregulation of microRNA-370 promotes cell apoptosis and inhibits proliferation by targeting PTEN in human gastric cancer. International journal of oncology. 2016; 49: 1589-99.

91. Liu Y, Sun Y, Zhao A. MicroRNA-134 suppresses cell proliferation in gastric cancer cells via targeting of GOLPH3. Oncology reports. 2017; 37: 2441-8.

92. Zhang $X$, Shi $\mathrm{H}$, Tang $\mathrm{H}$, Fang $\mathrm{Z}$, Wang J, Cui S miR-218 inhibits the invasion and migration of colon cancer cells by targeting the PI3K/Akt/mTOR signaling pathway. International journal of molecular medicine. 2015; 35: 1301-8.

93. Fujino $Y$, Takeishi S, Nishida K, Okamoto K, Muguruma N, Kimura T, et al Downregulation of microRNA-100/microRNA-125b is associated with lymph node metastasis in early colorectal cancer with submucosal invasion. Cancer science. 2017; 108: 390-7.

94. Tang RY, Wang Z, Chen HQ, Zhu SB. Negative Correlation between miR-200c and Decorin Plays an Important Role in the Pathogenesis of Colorectal Carcinoma. BioMed research international. 2017; 2017: 1038984.

95. Damsky W, Micevic G, Meeth K, Muthusamy V, Curley DP, Santhanakrishnan $\mathrm{M}$, et al. mTORC1 activation blocks BrafV600E-induced growth arrest but is insufficient for melanoma formation. Cancer cell. 2015; 27: 41-56.

96. Cui J, Lu K, Shi Y, Chen B, Tan SH, Gong Z, et al. Integrated and comparative miRNA analysis of starvation-induced autophagy in mouse embryonic fibroblasts. Gene. 2015; 571: 194-204

97. Qi L, Toyoda H, Xu DQ, Zhou Y, Sakurai N, Amano K, et al. Erratum to: PDK1-mTOR signaling pathway inhibitors reduce cell proliferation in MK2206 resistant neuroblastoma cells. Cancer cell international. 2015; 15: 108.

98. Krepler C, Xiao M, Sproesser K, Brafford PA, Shannan B, Beqiri M, et al. Personalized Preclinical Trials in BRAF Inhibitor-Resistant Patient-Derived Xenograft Models Identify Second-Line Combination Therapies. Clinical cancer research : an official journal of the American Association for Cancer Research. 2016; 22: 1592-602.

99. Wang Z, Ma B, Ji X, Deng Y, Zhang T, Zhang X, et al. MicroRNA-378-5p suppresses cell proliferation and induces apoptosis in colorectal cancer cells by targeting BRAF. Cancer cell international. 2015; 15: 40.

100. Titov SE, Ivanov MK, Karpinskaya EV, Tsivlikova EV, Shevchenko SP, Veryaskina YA, et al. miRNA profiling, detection of BRAF V600E mutation and RET-PTC1 translocation in patients from Novosibirsk oblast (Russia) with different types of thyroid tumors. BMC cancer. 2016; 16: 201.

101. Maadi H, Moshtaghian A, Taha MF, Mowla SJ, Kazeroonian A, Haass NK, et al. Multimodal tumor suppression by miR-302 cluster in melanoma and colon cancer. The international journal of biochemistry \& cell biology. 2016; 81: $121-32$
102. Chou CK, Liu RT, Kang HY MicroRNA-146b: A Novel Biomarker and Therapeutic Target for Human Papillary Thyroid Cancer. International journal of molecular sciences. 2017; 18 .

103. Bouchie A. First microRNA mimic enters clinic. Nature biotechnology. 2013; 31: 577 .

104. Adams BD, Parsons C, Slack FJ. The tumor-suppressive and potential therapeutic functions of miR-34a in epithelial carcinomas. Expert opinion on therapeutic targets. 2016; 20: 737-53

105. Cui J, Mo J, Luo M, Yu Q, Zhou S, Li T, et al. c-Myc-activated long non-coding RNA H19 downregulates miR-107 and promotes cell cycle progression of non-small cell lung cancer. International journal of clinical and experimental pathology. 2015; 8: 12400-9.

106. Li YL, Wang J, Zhang CY, Shen YQ, Wang HM, Ding L, et al. MiR-146a-5p inhibits cell proliferation and cell cycle progression in NSCLC cell lines by targeting CCND1 and CCND2. Oncotarget. 2016; 7: 59287-98.

107. Ma ZL, Zhang BJ, Wang DT, Li X, Wei JL, Zhao BT, et al. Tanshinones suppress AURKA through up-regulation of miR-32 expression in non-small cell lung cancer. Oncotarget. 2015; 6: 20111-20.

108. Liang C, Zhang X, Wang HM, Liu XM, Zhang XJ, Zheng B, et al. MicroRNA-18a-5p functions as an oncogene by directly targeting IRF2 in lung cancer. Cell death \& disease. 2017; 8: e2764.

109. Ma Z, Qiu X, Wang D, Li Y, Zhang B, Yuan T, et al. MiR-181a-5p inhibits cell proliferation and migration by targeting Kras in non-small cell lung cancer A549 cells. Acta biochimica et biophysica Sinica. 2015; 47: 630-8.

110. Shao Y, Shen YQ, Li YL, Liang C, Zhang BJ, Lu SD, et al. Direct repression of the oncogene CDK4 by the tumor suppressor miR-486-5p in non-small cell lung cancer. Oncotarget. 2016; 7: 34011-21.

111. Ma ZL, Hou PP, Li YL, Wang DT, Yuan TW, Wei JL, et al. MicroRNA-34a inhibits the proliferation and promotes the apoptosis of non-small cell lung cancer H1299 cell line by targeting TGFbetaR2. Tumour biology : the journal of the International Society for Oncodevelopmental Biology and Medicine. 2015; 36: $2481-90$

112. Wang DT, Ma ZL, Li YL, Wang YQ, Zhao BT, Wei JL, et al. miR-150, p53 protein and relevant miRNAs consist of a regulatory network in NSCLC tumorigenesis. Oncology reports. 2013; 30: 492-8.

113. de Melo AC, Grazziotin-Reisner R, Erlich F, Fontes Dias MS, Moralez G, Carneiro M, et al. A phase I study of mTOR inhibitor everolimus in association with cisplatin and radiotherapy for the treatment of locally advanced cervix cancer: PHOENIX I. Cancer chemotherapy and pharmacology. 2016.

114. Karandish F, Mallik S. Biomarkers and Targeted Therapy in Pancreatic Cancer. Biomarkers in cancer. 2016; 8: 27-35.

115. Fennell D. miR-16: expanding the range of molecular targets in mesothelioma. The Lancet Oncology. 2017

116. Souza MF, Kuasne H, Barros-Filho MC, Ciliao HL, Marchi FA, Fuganti PE, et al. Circulating mRNAs and miRNAs as candidate markers for the diagnosis and prognosis of prostate cancer. PloS one. 2017; 12: e0184094.

117. Gao H, Jin H, Li G. Predicting miRNA targets for head and neck squamous cell carcinoma using an ensemble method. The International journal of biological markers. 2017: 0

118. Yao K, Wang Q, Jia J, Zhao H. A competing endogenous RNA network identifies novel mRNA, miRNA and lncRNA markers for the prognosis of diabetic pancreatic cancer. Tumour biology : the journal of the International Society for Oncodevelopmental Biology and Medicine. 2017; 39: 1010428317707882 